\title{
Emergencia de la juventud en las ciudades contemporáneas
}

\author{
Ángela Garcés Montoya*
}

Recibido: 7 de abril de 2009

Aprobado: 1 de mayo de 2009

\begin{abstract}
RESUMEN
Este artículo presenta resultados de la investigación Mediaciones musicales juveniles, realizada en el año 2005. El Grupo de investigación Discurso, Organización y Política, indaga de forma espacial, por la emergencia y consolidación de los estilos y las culturas juveniles, asociados unos a los consumos culturales; otros, a la renovación cultural que logran los jóvenes a través de la música. Considera una compleja dimensión simbólica, que configura las formas de agregación y organización juvenil. Entre estilos y culturas juveniles desarrollamos un debate que resignifica y recrea la noción de tribus urbanas, contracultura y subculturas juveniles. Mientras en los estilos juveniles encontramos nuevas nociones que aluden a atmósferas y universos juveniles.
\end{abstract}

Palabras clave: estilos juveniles, culturas juveniles, Juventud.

Historiadora, Magíster en Estética. Lidera el Grupo de Investigación Discurso, Organización y Política con la Línea de Investigación Comunicación y Culturas juveniles. Clasificado en A (máxima calificación de COLCIENCIAS) Docente - Investigadora de la Facultad de Comunicación, Universidad de Medellín. E-mail: agarces@udem.edu.co / culturasjuveniles@gmail.com 


\title{
Young People's Emergence in Contemporary Cities
}

\begin{abstract}
This article shows the results of a research called "Youth Musical Measurements," conducted in year 2005. Research Group "Speech, Organization, and Politics" makes a partial investigation about emergence and consolidation of young styles and cultures associated to cultural consumption and to cultural renewal achieved by young people through music. The article considers a complex symbolic dimension, ways of grouping, and organization. Speaking about young styles and cultures, we develop a debate which gives a new meaning and recreates the notion of young urban tribes, counter-culture, and sub-cultures. In relation to young styles, we find new notions which allude to young atmospheres and universes.
\end{abstract}

Key words: young styles, young cultures, youth. 


\section{EMERGENCIA DE LA JUVENTUD}

Al recorrer el siglo XX en función de las representaciones de juventud, se reitera cómo la condición de juvenil es representada, y las diversas derivas de su representación están en función de los imaginarios sociales dominantes que definen a los grupos portadores de la condición juvenil, y frente a ellos aparecen los otros discursos, que tratan de desestabilizar la imagen estereotipada de la juventud. Por ello, es conveniente revisar las condiciones sociales y culturales que permiten la emergencia de lo juvenil siempre relativa al tiempo y al espacio, pues los jóvenes son sujetos sociales relacionales, y su existencia será híbrida y cambiante, y dependerá de variables interdependientes como edad, clase social, género, generación, estética, cuerpo, poder...

Para sustentar la noción la condición juvenil es representada, se retoma la reflexión del investigador José Antonio Pérez Islas (1998), al pensar los enfoques contemporáneos de los estudios sobre juventud:

La cultura juvenil ya no necesariamente se ubica en un solo sector de los jóvenes (como fue el caso de los estudiantes de los setenta o las banda juveniles de los ochenta); pareciera que hay una preocupación por saber qué está pasando en las mayorías silenciosas que pueblan nuestras ciudades; la conciencia de que no hay una juventud, sino juventudes, espacialmente ubicadas y temporalmente construidas, es un gran logro de las teorías generales de la cultura juvenil.

Otro avance en los estudios de juventud tiene que ver con los intentos de superar la concepción de los jóvenes como receptores pasivos de los procesos de inculcación y formación que las diversas instituciones realizan sobre las nuevas generaciones. Las adaptaciones que a la cultura mass mediática realizan los jóvenes, las prácticas alternativas juveniles y las producciones de significado propias que generan implican una visión diferente de los significantes que implica ser joven, no como sujeto sujetado sin más, sino como un actor decisivo en la construcción de su propia identidad (Pérez, 1988, p.p 46 - 56).

En ese panorama es importante revisar la relación de los jóvenes con la cultura, al ser necesario marcar la diferencia entre jóvenes que viven la cultura como receptores pasivos frente a otros jóvenes disidentes, que se declaran productores y renovadores de cultura. Si bien, nuestra investigación en Culturas juveniles contemporáneas (2005) reconoce y valora la existencia de jóvenes que configuran su identidad a través de las adscripciones a los mundos musicales que les permiten configurar proyectos vitales de vida, denominados culturas juveniles, es inevitable reconocer cómo las industrias culturales configuran y moldean estilos juveniles dispuestos en y para el consumo permanente que son estilos efímeros, cambiantes, pasajeros.

En las culturas juveniles, los jóvenes logran a través de la música, configurar diversas y complejas formas de agregación y organización juvenil, que desde el sentido popular juvenil resignifican y recrean la noción de tribus urbanas, contracultura y subculturas juveniles, mientras que en los estilos juveniles encontramos nuevas nociones que aluden a atmósferas y universos juveniles.

Esas diversidades que rondan el concepto de juventud nos obligan a pensar en los obstáculos epistemológicos, que impiden su posicionamiento y validación en los estudios culturales. En particular, nos recuerda Roberto Brito Lemus (1999) que "no podemos confundir un criterio demográfico (la edad) con un fenómeno socio-cultural". Según este autor (Brito, 1999, p.p 26-27), se pueden mencionar algunos obstáculos en la conceptualización de juventud, como: 
- Debido a su uso común ha adquirido innumerables significados: sirve tanto para designar un estado de ánimo, como para calificar lo novedoso y actual, incluso se considera un valor en sí mismo.

- La juventud presenta en la sociedad actual alta diversidad, abarca desde un "chavo banda" a un joven de clase alta, un joven campesino, un joven obrero. Destacan las diferencias de clase por encima de las representaciones de la juventud.

- La juventud no es un "don" que se pierde con el tiempo, sino una condición social con cualidades específicas que se manifiestan de diferente manera, según las características históricas y sociales de cada sujeto.

- En relación con la duración de la juventud, se evidencia que no tiene la misma duración en el campo que en la ciudad; en las clases altas que en los sectores populares; en las sociedades modernas que en las tradicionales, incluso hay diferencias entre los géneros (masculino / femenino).

\section{¿ACASO LA HISTORIA HABLA DE JUVENTUD?}

La juventud como concepto presenta un sentido polisémico, en tanto es necesario entenderlo como una construcción sociocultural, diversa en el tiempo y en el espacio. Hablar de juventud implica, entonces, asumir a la vez una precisión histórica y regional, para poder reconocer las diferencias y particularidades definidas por sus contextos sociales, culturales y territoriales (Valenzuela, 1998, Reguillo 2000, Garcés 2005).

La juventud entonces es un concepto en construcción, y se reconoce que responde a procesos socio-históricos, relacionales y situacionales conformados en la mediación de lo individual y lo colectivo. Por ello, las identificaciones sociales juveniles se producen dentro de campos relacionales de auto percepciones, y la auto identificación se inscribe en campos de relaciones sociales que hacen aparecer como "normales" las formas de identificación y conducta legitimadas por los grupos dominantes; por ello, resulta importante considerar el reconocimiento de auto identificaciones juveniles, estigmatizadas por grupos sociales dominantes y claramente cuestionadas por los sectores más intransigentes de la sociedad. Como lo enuncia Manuel Valenzuela (2005):

La juventud alude a construcciones heterogéneas históricamente significadas dentro de ámbitos relacionales y situacionales. Ubicar la condición histórica de los estilos de vida y praxis juveniles supone reconocer sus diversidades y transformaciones. Por ello, el tema de juventudes implica asumir una dimensión diacrónica del concepto, pero también su heterogeneidad sincrónica (Valenzuela, 2005, p.28)

Podríamos decir que la juventud, como la conocemos hoy, surge en el siglo XX, asociada a diversas "Revoluciones", industriales, culturales, sociales, relacionadas con

- Crecimiento de las ciudades: se configuran grandes ciudades y metrópolis que concentran la economía, la educación y el desarrollo en transporte, comunicación y cultura.

- A su vez, el crecimiento de la ciudades ocasiona grandes migraciones campesinas, con un crecimiento radial de las ciudades con su correspondiente sectorización espacial (clases altas, medias, marginales)

- Nueva noción de educación asociada a la "escuela" como espacio de formación que permite la definición de trayectos de vida distintos a los conformados por adscripción laboral, o la derivada de la actividad de los padres, propia de ámbitos familiares. 
- Las nuevas tecnologías se convierten en la renovada fuente de conocimiento para los jóvenes, espacios y dominios de difícil acceso para el mundo adulto.

El siglo XX se corresponde con la emergencia de la juventud. Como bien lo enuncia José Manuel Valenzuela (2005):

Con el siglo XX se desarrollan nuevas formas de sociabilidad juvenil, propiciadas por el crecimiento de la vida urbana, el desarrollo de los medios de comunicación y de transporte, la masificación de la escolaridad y un importante crecimiento de los sectores medios. Muchos jóvenes accedieron a nuevos tiempos y espacios. Mientras que los jóvenes de las clases medias y altas comenzaron a apropiarse de los clubes, cafés, boliches y bares, lo pobres se apropiaron de las calles y los barrios (Valenzuela, 2005, p. 9).

Se reconoce, entonces, que durante el siglo XX la condición juvenil ha dejado de ser una categoría residual. Paulatinamente ha ganado espacio en los estudios socio-culturales, aunque ha necesitado de tiempo y revisiones conceptuales, que permitan la depuración de los estudios de juventud, que avancen de las representaciones juveniles basadas en estereotipos a las representaciones positivas, que reconozcan producción y gestión cultural juvenil.

En relación con las Imágenes de juventud, pareciera que esa condición fuera inherente al ser masculino. Si recorremos la historia universal vemos que hasta el siglo XX, sólo se reconoce una diversidad de expresiones e instituciones sociales que permiten la existencia restringida de modelos de juventud, con una particularidad: se trata de "jóvenes varones"; la mujer y su juventud quedan excluidas en los imaginarios sociales.

No todas las sociedades reconocen un estadio nítidamente diferenciado entre la dependen- cia infantil y la autonomía adulta. En nuestro caso particular, la historia local de Medellín reporta que las generaciones propiamente urbanas comienzan a registrarse muy tardíamente (década del 60), pues somos hijos de migrantes campesinos, que difícilmente conocieron y vivieron la juventud, en tanto es común la entrada precoz del niño(a) a la vida adulta, en una sociedad con baja cobertura de escuelas, donde la socialización se da en primer lugar en el trabajo en común: los niños en el campo, las niñas en las labores domésticas, cumpliendo rápidamente el relevo familiar.

Al recurrir a la historia universal, se reconoce una diversidad de expresiones e instituciones sociales que permiten la existencia de tres grandes modelos de juventud, con una particularidad: se trata de la existencia de "jóvenes varones"; la mujer y su juventud quedan excluidas, pues se entiende que la juventud en clave de género merece atender las historias particulares, pero nuestros derroteros investigativos siguen transitando por las expresiones masculinas.

Veamos entonces esos modelos masculinos:

- Púberes. En las sociedades "primitivas" mejor llamadas "ancestrales" es claro encontrar el valor otorgado a la pubertad como límite fundamental en el curso de la vida. Así, a partir de los "ritos de iniciación" se establece que, en determinado momento de la vida, el niño y la niña deben morir simbólicamente para transformarse en adultos. Los diversos ritos se acompañan de alucinógenos, aislamiento y ayuno que aportan a la percepción de muerte y de renacimiento. Después del rito de paso, el niño o la niña se transforman en hombre y mujer, pueden entonces pensar en casarse, tener hijos y participar en actividades de los adultos.

En esas sociedades, si bien se reconoce una fase de transición entre la infancia y la adultez, es 
evidente que no existe un largo estadio de transición previo a la plena inserción social, ni tampoco existe un conjunto de imágenes culturales que distingan claramente este grupo de edad de otros.

- Efebos. Los efebos tienen lugar en la sociedad clásica griega, donde la juventud es considerada una edad modelo. El término efebo significa etimológicamente "el que ha llegado a la pubertad"; además del fenómeno fisiológico, tiene un sentido jurídico, ético y erótico. Se trata del reconocimiento público del fin de la infancia para iniciar el período obligatorio de noviciado social -la efebía- entendida como la institución militar y filosófica de preparación de los jóvenes guerreros entre los 16 y 21 años; una preparación que incluye ejercicios físicos, morales y eróticos, regidos por un período de aislamiento social y reunión entre hombres. La práctica de la efebía también se extiende a la sociedad greco-romana donde también existe la transición del púber en adulto.

- Mozos. En la Europa medieval y moderna, lo que se conoce como sociedad de Antiguo Régimen no es fácil identificar una fase de la vida que se corresponda con lo que hoy entiende por juventud, aunque existen separaciones de períodos específicos que enuncian infancia, juventud y vejez, caso de la lengua francesa medieval.

En las sociedades campesinas ibéricas encontramos el término "mozo" $y$ "moza" que se atribuye a menores de edad como a solteros y sirvientes de manera relativamente independiente respecto a la edad cronológica. A su vez, si revisamos las imágenes iconográficas, encontramos que los niños son representados como "adultos en miniatura" y que no existe una imagen específica para los jóvenes (Philiphe Ariés, 1973, pp. 5-6).

Aunque es necesario reconocer la existencia de "sociedades de solteros", aquellos grupos de "jóvenes" en comunidades ruales del Antiguo Régimen, que cumplían una importante función en la organización de las fiestas y los juegos, en carnavales y además, se ocupaban de la defensa de la identidad local frente al exterior. Se insiste en que no se trata de una juventud propiamente dicha, sino de "sociedades de solteros" en unas sociedades campesinas donde las nociones de "casa" y "herencia" juegan un papel fundamental en el estatus familiar y social, pues a través de esas instituciones se marca la línea divisoria entre dependencia y emancipación.

\section{ESTEREOTIPOS QUE RONDAN LA JUVENTUD}

Las clasificaciones disponibles de juventud presentan prototipos diversos y cambiantes. Desde la filosofía en la antigua Grecia a los parámetros publicitarios modernos, la juventud se presenta con rasgos negativos.

Por ejemplo, si revisamos las imágenes de jóvenes en la Antigüedad griega, vemos cómo Aristóteles definió los rasgos del carácter típico de juventud, la madurez y la vejez. En relación con la juventud, afirma que los jóvenes son concupiscentes, decididos, hedonistas e incontinentes a los placeres del amor. Además, los consideró mudables, inestables, caprichosos, apasionados, impulsivos, animosos, de genio vivo, iracundos, amantes del prestigio y la victoria (Valenzuela, 2005).

Esas imágenes se corresponden con una clasificación y diferenciación entre hombres jóvenes, maduros y ancianos, donde se hace evidente un adultocentrismo, pues en los jóvenes reposan los atributos negativos, y en los adultos los atributos positivos.

Por ello, en un nivel intermedio entre los jóvenes y los ancianos, se encuentran los hombres maduros (siempre en masculino), quienes tienen lo mejor de los jóvenes y los ancianos en un punto intermedio, así que los hombres maduros son: 
Hombres ni muy confiados, ni muy temerosos, no sesgados hacia lo bello y lo útil, más bien ecuánimes. Los hombres maduros no son ni ultra ahorradores ni derrochadores, ni iracundos ni concupiscentes. Si los jóvenes son valerosos e intemperantes, los ancianos son temperantes pero cobardes, los hombres maduros son temperantes con fortaleza y fuertes con templanza, pues poseen lo mejor de atributos de jóvenes y viejos. Sin embargo la madurez es un proceso con fases desiguales pues la del cuerpo se obtiene entre los treinta y los treinta y cinco años, mientras que la del alma madura en torno de los cuarenta y nueve años (Valenzuela, 2005, p. 71)

El lenguaje publicitario se dirige a los jóvenes a partir de una gran cantidad de mensajes persuasivos, que determinan y orientan su comportamiento, en tanto la comunicación persuasiva posee la facultad de transmitir ideales, valores $\mathrm{y}$, sobre todo, estilos de vida, que influyen en el mundo juvenil. Esta afirmación se sustenta en varios presupuestos sobre la juventud, que están en relación con los estereotipos sociales y culturales atribuidos a ese grupo etario. Revisemos algunos:

- La juventud es una generación que no concibe el mundo sin publicidad. Afirmación que se sustenta al verificar que el joven ha llegado a integrar la publicidad en su entorno normal de vida y, por ello, la comunicación persuasiva a hecho del joven y sobre todo de la juventud un objeto permanente de operación.

- La juventud es una etapa marcada por la necesidad de autoafirmación combinada con un notable sentido de inseguridad. Bajo esa pre-concepción, la publicidad asume al joven como un sujeto influenciable y, además, vulnerable psicológicamente, por tanto, la comunicación persuasiva trabaja en la construcción de la identidad juvenil concebida como insegura, cambiante, frágil y fragmentada.
- La juventud es el paradigma de la publicidad, ese momento de la vida se presenta como algo a lo que hay que aspirar permanentemente, algo que hay que retener y, además, incorporar como un estilo de vida, pues "envejecer no está de moda".

De la filosofía a la publicidad se reconoce que los jóvenes son sujetos de restricciones y controles, pues se definen como seres amenazantes, al enfatizar sus apetitos y sus excesos, además de que alude a una condición juvenil incontinente, lasciva y desenfrenada a la que hay que controlar mediante recursos de disciplina y gobierno.

Según el estudio del Estado del arte nacional en investigación en juventud, registrado en los últimos 20 años (Escobar, 2006, p.p 188-190) se encuentran como aspectos relevantes las siguientes perspectivas investigativas, presentadas por el investigador Manuel Roberto Escobar que oscilan entre la estigmatización de los jóvenes o el reconocimiento de sujetos productores de cultura; veamos:

- Investigaciones basadas en jóvenes urbanos que asocian al joven con la vulnerabilidad y el riesgo, la búsqueda de identidad y el cambio social. En esta vía de sentidos, se representa al joven en relación con incompletud, transitoriedad y vulnerabilidad. El sujeto leído como carencia es por tanto susceptible de entrar en riesgos para sí mismo y/o constituirse en un peligroamenaza para la sociedad.

- Se reitera la ubicación del joven desde la perspectiva etaria, que se conjuga con la anterior orientación investigativa, que termina por atribuir las problemáticas juveniles a la edad en que se está, ya sea porque se asume que la biología determina conductas (por ejemplo desde "ajustes hormonales") o que la inserción en los roles sociales esperados demanda ajustes ("una etapa de crisis) y en algunos casos deriva en desviaciones o transgresiones. 
De otro, es necesario reconocer al joven como sujeto portador de una cultura, pero también con capacidad de incidir en ella, incluso de transformarla, allí los estudios culturales referidos a la juventud ofrecen diferentes tratamientos; entre ellos se destacan la participación y organización juvenil, los consumos culturales y los énfasis en las culturas y subjetividades juveniles; estudios interesados en la identificación, valoración y visibilización de los procesos de identificación juveniles y de los productos culturales asociados a los y las jóvenes agrupados. Se trata de múltiples vías para reconocer los procesos de identificación juvenil y su construcción cultural.

Gracias a ese enfoque no ha sido en vano la amplia trayectoria de investigaciones relacionadas con expresiones y prácticas juveniles que versan alrededor de culturas, tribus urbanas, contraculturas, en especial, desde los territorios musicales propios de la urbe: punk, reggaee, ska, electrónica, hip hop.

Las culturas juveniles urbanas se van configurando como espacios de identidad y socialización de jóvenes para jóvenes y se fortalecen con el debilitamiento de los mecanismos de integración tradicional (escuela, familia, trabajo, religión) y el descrédito de las instituciones políticas. En este contexto, adquieren relevancia los estudios culturales urbanos, donde los jóvenes aparecen como sujetos y grupos productores de cultura por sus maneras de entender y asumir el mundo. Las culturas juveniles urbanas operan como espacio de pertenencia y adscripción identitaria.

La anarquía, los grafitos urbanos, los ritmos tribales, los consumos culturales, la búsqueda de alternativas y los nomadismos urbanos, deben ser leídos como formas de producción cultural no institucionalizada [...] conformados por una multiplicidad de colectivos que están dinamizando día a día la sociedad y requieren ser estudiados "desde abajo", aunque plantean formas de organización y propuestas de gestión que escapan a las formas tradicionales de concebir los procesos de identidad y socialización entre jóvenes. (Reguillo, 2000, p.14)

Una revisión bibliográfica en Iberoamérica nos constata el amplio avance de la investigación en culturas juveniles, donde resaltan en México las investigaciones de Rossana Reguillo Cruz y José Manuel Valenzuela; con ellos identificamos las expresiones locales, como son los taggers, rastecas, ravers (Reguillo, 2000), cholos, chavos y pachuchos (Valenzuela, 1997 y 1998). En España, encontramos al antropólogo Carles Feixa Pampols, con estudios locales para Cataluña y estudios comparados entre España y México relacionados con el mundo punk (Feixa, 1998 y 1999). En Guayaquil, Ecuador, sobresale la compilación realizada por Mauro Cerbino (2000), titulada Culturas juveniles en Guayaquil, donde presenta ensayos teóricos que abordan la construcción de sentidos juveniles a partir de la resignificación del cuerpo, la fiesta y las sensibilidades juveniles, con tratamientos especializados basados en semiótica cultural, diferenciación de género y comunidades emocionales. En Argentina, Mario Margullis (1994) aborda la vida nocturna de los jóvenes en Buenos Aires en su texto Culturas de la noche, e identifica las culturas juveniles en relación con las ofertas musicales de la noche urbana a través de cuatro géneros: la discoteca, el rock, la bailanta y los modernos.

La reflexión sobre los procesos de identificación de los jóvenes urbanos a través de las culturas juveniles ha sido ampliamente desarrollada por Rossana Reguillo en su libro Emergencias de las culturas juveniles. Estrategias del desencanto; allí propone como variables de análisis la socio-estética, el territorio y las microdisidencias que permiten entender la emergencia de las culturas juveniles. 


\section{A MANERA DE CIERRE: HABLEMOS DE DISIDENCIA JUVENIL}

Para pensar los discursos de resistencia juvenil es necesario hacer un recorrido entre movimientos y expresiones juveniles, que tienen un contexto especialmente urbano en tanto cobran vigencia con los procesos de modernización e integración del país al mercado internacional que caracteriza los inicios del siglo XX. Proceso de modernización económica y social que envuelve "desarrollos desiguales" y "discontinuidades culturales" (Barbero, 1996) a partir de las cuales los jóvenes expresan oposición, confrontación y movilización ante el discurso dominante.

Uno de los discursos de resistencia apropiado y resignificado por los jóvenes es el movimiento Contracultural. Según José Agustín contracultura

... es toda una serie de movimientos y expresiones culturales, regularmente juveniles, colectivos, que rebasan, rechazan, se marginan, se enfrentan o trascienden la cultura institucional. Y por cultura institucional se da a entender a la cultura dominante, dirigida, heredada y con cambios para que nada cambie, muchas veces irracional, generalmente enajenante, deshumanizante, que consolida al statu quo y obstruye, si no es que destruye, las posibilidades de una expresión auténtica entre jóvenes, además de que aceita la opresión, la represión y la explotación por parte de los que ejercen el poder, naciones, centros financieros o individuos (Citado por Zarzuri, 1998).

La contracultura sabe cuánto poder corrosivo logra ante el discurso dominante y, por tanto, su oposición se sitúa en la margen y trata de mantener y regular sus propios medios de circulación, denominados underground. Por eso, quizá, entre los discursos de resistencia juvenil y los discursos publicitarios sobre la juventud sea necesario resaltar cómo en los primeros predomina la construcción creativa de la identidad marcada por múltiples carencias (sociales, económicas y urbanísticas); mientras en los segundos se encuentra una imagen de joven asociada a bienestar y confort, un joven con suficiente capacidad de consumo que juega a la relación tener - ser; se trata de "jóvenes sin problemas".

\section{REFERENCIAS BIBLIOGRÁFICAS}

Brito, R (1996). Hacía una sociología de la juventud. En: Revista Jóvenes. Año 1, No. 1 (julio - septiembre).

Garcés, A. (2005). Nos-otros los jóvenes. Polisemias y territorios musicales en Medellín. Medellín: Sello Editorial Universidad de Medellín.

Escobar, M. (2006). Estado del Arte del conocimiento producido sobre jóvenes en Colombia, 1985-2003. GTZUNICEF Colombia, 2006. www.colombiajoven.gov.co.

Feixa, C. (1998) El reloj de arena. Culturas juveniles en México. México: Causa Joven-CIEJ.

(1999) De jóvenes, bandas y tribus. Antropología de la juventud. Barcelona: Ariel.

Marguills, M (1994). La cultura de la noche: la vida nocturna de los jóvenes en Buenos Aires. Argentina: Espasa Hoy.

Martín-Barbero. (1996) Comunicación y ciudad: sensibilidades, paradigmas, escenarios. En: GIRALDO, Fabio. (Compilador). Pensar la ciudad. Bogotá: TM. 
Pérez, J. (1998) Memoria y olvidos. Una revisión sobre el vínculo de los cultural y lo juvenil”. En: Viviendo a toda. Jóvenes, territorios culturales y nuevas sensibilidades. Bogotá: Siglo del hombre Editores. Departamento de investigaciones de la Universidad Central.

Reguillo, R. (2000). Emergencia de las culturas juveniles: estrategias del desencanto. Bogotá: Norma.

Valenzuela, J. (2005). El futuro ya fue. Juventud, educación y cultura. En: Anales de Educación Común. Año 1, No. 1-2. Dirección General de Cultura y Educación de la Provincia de Buenos Aires.

Zarzuri, R. (1998) La contracultura. Santiago: Ediciones Ucsh 